\title{
Extracorporeal Shockwave Therapy for Painful Chronic Traumatic Heterotopic Ossification after Right Acetabulum Fracture Fixation: A Case Report and Literature Review
}

\author{
Mohieldin M. Ahmed ${ }^{1 *}$, Shothour M. Alghunaim², Douaa M. Mosalem², Sherif M. Khairat ${ }^{2}$, Farah Abdel Hameed ${ }^{3}$ \\ ${ }^{1}$ Department of Physical Medicine and Rehabilitation, Amiri Hospital, Ministry of Health, Kuwait; ${ }^{2}$ Department of Physical \\ Medicine and Rehabilitation, Al-Razi Hospital, Ministry of Health, Kuwait; ${ }^{3}$ Medical Student, University of Birmingham, United \\ Kingdom
}

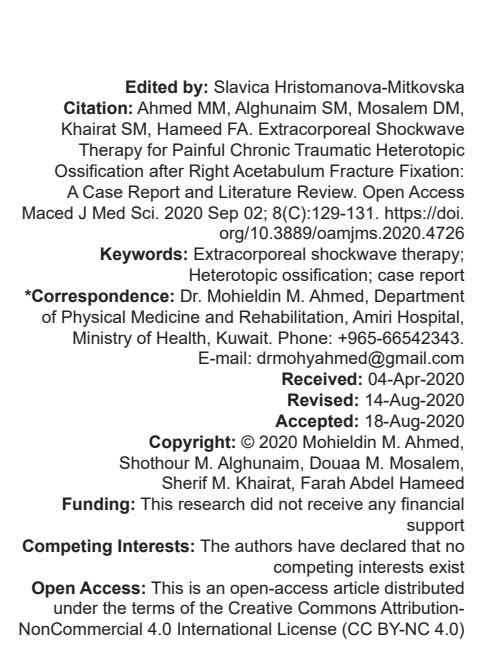

\begin{abstract}
BACKGROUND: Heterotopic ossification (HO) usually occurs in trauma, such as fractures. To the best of our knowledge, there is a lack of studies about the effects of shockwave on the size of $\mathrm{HO}$ in the literature.

AIM: The aim of this study was to describe the effects of extracorporeal shockwave therapy (ESWT) on the size of $\mathrm{HO}$ as well as the lower extremity functions in patients with fracture right acetabulum.

CASE REPORT: A 36-year-old gentleman had a traffic accident on August 30, 2015, resulted in a fracture of the right acetabulum treated by open reduction and internal fixation on September 2, 2015. The patient has complained of severe right hip pain with limitation of daily activities, especially walking, standing, and sitting, visual analog scale about 7-8/10 with painful and restricted ROM of the right hip. Plain X-ray of the right hip revealed $\mathrm{HO}$ at greater trochanter with a long axis length $37.3 \mathrm{~mm}$. ESWT was applied for HO. ESWT was administered 6 times each weekly for 6 weeks. At 6 -month follow-up, the size of $\mathrm{HO}$ had become slightly smaller with the improvement of pain, and
\end{abstract} lower extremities functions.

DISCUSSION: Soft tissues around HO have been regenerated from ischemia for several reasons such as ESWT stimulating angiogenesis and neurogenesis and the size of $\mathrm{HO}$ had become slightly smaller by radial shockwave therapy.

CONCLUSION: ESWT is a novel non-invasive and safe treatment for HO. The effects of ESWT on the size of HO had become slightly smaller with the improvement of lower extremities functions.

\section{Introduction}

Heterotopic ossification ( $\mathrm{HO})$ is defined as bone formation in non-osseous tissues. HO usually occurs in trauma such as fractures and surgical procedures of the hip. Traumatic HO occurs in 10-20\% of predisposed patients [1]. Extracorporeal shockwave therapy (ESWT) generates pressure waves through the collision of solid bodies [2]. It has been widely used to treat various musculoskeletal injuries [3], [4].

To the best of our knowledge, few reports have been reported about the effects of ESWT on the size of $\mathrm{HO}$ as well as functions of the lower extremity in the literature. Thus, the objective is to describe the effects of ESWT on the size of $\mathrm{HO}$ as well as the lower extremity functions in patients with fracture right acetabulum. Thus, the objective is to describe the effects of ESWT on the size of $\mathrm{HO}$ as well as the lower extremity functions in patients with fracture right acetabulum.

\section{Case Presentation}

A 36-year-old male with no notable medical history had been involved in a traffic accident on August 30, 2015, resulted in fracture right acetabulum and fracture left clavicle. Fracture right acetabulum treated by open reduction and internal fixation on September 2 , 2015. Fracture left clavicle treated conservatively.

The patient came to the physical medicine and rehabilitation department at Al Razi hospital in Kuwait referred from orthopedic doctor complaining of severe right hip pain which affects his ADL activities, especially walking, standing, and sitting. Clinically, his visual analog scale was 7-8/10 with a painful limited range of motion (ROM) of the right hip. Passive ROM of the left hip was restrictively measured using a goniometer in a supine position due to pain.

Plain X-ray of the right hip was done and revealed $\mathrm{HO}$ at greater trochanter and femoral head with long axis length for greater trochanter $\mathrm{HO} 37.3 \mathrm{~mm}$ 
(Figure 1). ESWT was applied using Piezo shockwave (Richard Wolf, century, Germany) for the right hip HO because conservative treatments were ineffective. Each application of ESWT used 3000 shocks at the rate of $5 \mathrm{~Hz}$ and the energy flux density between 0.064 and $0.139 \mathrm{~mJ} / \mathrm{mm}^{2}$ (intensity 10 18) and ESWT was administered 6 times each weekly. During the 6 weeks of the treatment period, the subject tolerated ESWT treatments, and no serious side effects were observed.

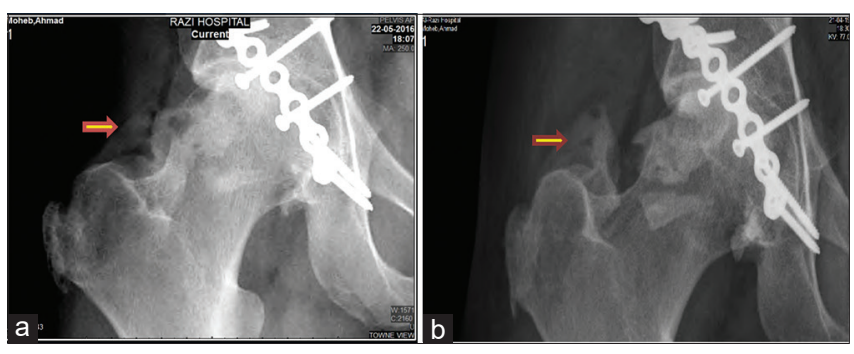

Figure 1: (a) Radiograph of the right hip showed before extracorporeal shockwave therapy (ESWT). (b) Radiograph of the right hip showed after ESWT. The size of the heterotopic ossification had become slightly smaller

At 5-month follow-up, he got an improvement of his daily activities, especially walking and sitting, reduction of pain with visual analog scale about $1 / 10$ and increased ROM of right hip (Table 1).

Table 1: Measurements of clinical outcomes during the treatment period of heterotopic ossification in patients with fracture right acetabulum

\begin{tabular}{lllll}
\hline Clinical outcome & $\begin{array}{l}\text { Before } \\
\text { ESWT }\end{array}$ & $\begin{array}{l}\text { After 3 weeks } \\
\text { of ESWT }\end{array}$ & $\begin{array}{l}\text { After 6 weeks } \\
\text { of ESWT }\end{array}$ & $\begin{array}{l}\text { After 6 } \\
\text { months }\end{array}$ \\
\hline VAS & $7-8$ & 3 & 1 & 0 \\
Functional activity & 4 & 3 & 2 & 1 \\
ROM & & & 90 & 110 \\
$\quad$ Flexion & 80 & 90 & 30 & 30 \\
$\quad$ Abduction & 15 & 20 & 15 & 20 \\
$\quad$ Internal rotation & 10 & 15 & 20 & 30 \\
$\quad$ External rotation & 15 & 20 & 5 & 5 \\
$\quad$ Extension & 0 & 5 & & \\
\hline
\end{tabular}

Moreover, we found that the effects of ESWT on the size of $\mathrm{HO}$ had become slightly smaller in our patient with the improvement of pain, ROM, muscle strength, and lower extremities functions (Table 1 and Figure 1).

\section{Discussion}

$\mathrm{HO}$ is defined as bone formation in nonosseous tissues. HO usually occurs in trauma such as fractures and surgical procedures of the hip. Traumatic $\mathrm{HO}$ occurs in $10-20 \%$ of predisposed patients [1]. Traumatic $\mathrm{HO}$ causes significant morbidity, including pain and loss of motion, especially around joints and can significantly impair quality of life. Therefore, it seems desirable to find ways of either preventing or treating this pathological process for improved rehabilitation [1].

Traumatic HO causes significant morbidity, including pain and loss of motion, especially around joints and can significantly impair quality of life. Therefore, it seems desirable to find ways of either preventing or treating this pathological process for improved rehabilitation. There are several studies reported, where ESWT was effective in relieving pain caused by mature $\mathrm{HO}$ [5], [6].

In our patient, we found that the effects of ESWT on the size of $\mathrm{HO}$ had become slightly smaller in our patient with improvement of pain, ROM, muscle strength, and lower extremities functions. Other authors reported that functionally significant deficits typically occur in 10-20 \% of patients [7]. Symptoms tend to be localized and usually consist of localized swelling, tenderness, and decreased mobility of adjacent joint [7]. Kim et al. 2017 found that radial shockwave therapy revealed that the size had become slightly smaller in post-treatment on both right and left neurogenic $\mathrm{HO}$ in comparison to X-rays pre-treatment and post-treatment [8]

The basic mechanism of traumatic $\mathrm{HO}$ of muscle may result from the proliferation of fibroblast, bone, and cartilage usually after an inciting event, the process is initiated by trauma in 60 to $75 \%$ of cases [9]. The inciting trauma stimulates and inflammatory response mediated the rough hematoma formation followed by a cascade of events. Most cases occur in the first three decades of life. The most common locations include the thigh, hip, upper arm, calf, and foot [9].

There have been no clear explanations about the effects of ESWT on HO. However, the basic mechanism of effect of ESWT on HO was hypothesized that after applying ESWT, soft tissues around $\mathrm{HO}$ have been regenerated from ischemia for several reasons such as ESWT stimulating angiogenesis (new blood vessels) and neurogenesis (new nerve cells) [10].

\section{Conclusion}

ESWT is a novel non-invasive and safe treatment for reducing pain resulting from traumatic $\mathrm{HO}$ in patients with fracture right acetabulum. The effects of ESWT on the size of HO had become slightly smaller with the improvement of pain, ROM, muscle strength, and lower extremities functions of the patient. Moreover, ESWT might be an interesting treatment for traumatic $\mathrm{HO}$ and can be a complement to usual medical treatment, physiotherapy, and before surgery.

\section{Consent for Publication}

Oral informed consent was obtained from the patient for publication of this case report and any accompanying images. 


\section{Acknowledgments}

The author is grateful to this patient that participated in this study and to our colleagues for their assistance for the review of the manuscript.

\section{References}

1. Pacos EE, Stafilas KS, Tsekeris PG, Politic AN, Mitsionis G, Xenakis TA. Combined radiotherapy and indomethacin for the prevention of heterotopic ossification after total hip arthroplasty. Strahlenther Onkol. 2009;185(8):500-5. https://doi.org/10.1007/ s00066-009-1954-3

PMid:19652932

2. Gleitz M. Myofascial Syndromes and Trigger Points-shock Wave Therapy in Practice. $1^{\text {st }}$ ed. Heilbronn: Publishig House; 2011. p. 208.

3. Moon SH, Lee S, Kim KH. Ultrasound-guided exact focusing of extracorporeal shock wave therapy for the calcific tendinitis of gluteus medius-a case report. J Korean Orthop US Soc. 2012;5:94-8.

4. Cho YS, Park SJ, Jand SH. Effects of the combined treatment of extracorporeal shock wave therapy (ESWT) and stabilization exercises on pain and functions of patients with myofascial pain syndrome. J Phys Ther Sci. 2012;24:1319-23. https://doi. org/10.1589/jpts.24.1319

5. Brissot R, Lassalle A, Vincendeau S, Polard JL, Fouche M, Ninubona $\mathrm{D}$, et al. Treatment of heterotopic ossification by extracorporeal shock wave: 26 patients. Ann Readapt Med Phys. 2005;48(8):581-9. https://doi.org/10.1016/j.annrmp.2005.04.014 PMid: 15993976

6. Reznik JE, Milanese S, Golledge J, Biros E, Gordon S, Galea MP. Extracorporeal shock wave therapy as a treatment for heterotopic ossification. Phys Ther Rev. 2013;18:300-7. https://doi.org/10.1179/1743288x13y.0000000084

7. Rothwell AG. Quadriceps hematoma: A prospective clinical study. Clin Orthop Relat Res. 1982;171:97-103.

PMid:6814806

8. Kim H, Cheon JH, Lee DY, Cheon JH, Cho YK, Lee SH, et al. Intramuscular hematoma following radial extracorporeal shockwave therapy for chronicneurogenic heterotopic ossification: A case report. Ann Rehabil Med. 2017:41(3):498504. https://doi.org/10.5535/arm.2017.41.3.498

PMid:28758090

9. Mc Carthy E. Heterotopic ossification: A review. Skeletal Radial. 2005;34(10):609-919.

PMid: 16132978

10. Choi YM, Hong SH, Lee CH, Kang JH, Oh JS. Extracorporeal shock wave therapy for painful chronic neurogenic heterotopic ossification after traumatic brain injury: A case report. Ann Rehabil Med. 2015;39:318-22. https://doi.org/10.5535/arm.2015.39.2.318 PMid:25932431 